\title{
METHOD TOOLBOX FOR THE MULTIDISCIPLINARY PLANNING AND DEVELOPMENT OF ADAPTIVE BUILDINGS
}

\author{
Honold, Clemens; Leistner, Sophia; Roth, Daniel; Binz, Hansgeorg; Sobek, Werner \\ University of Stuttgart
}

\begin{abstract}
Adaptive buildings constitute an interdisciplinary approach for realizing the next generation of buildings in order to reduce the immense material requirements and energy demand throughout all lifecycle phases. Based on a novel cooperation between the disciplines of Architecture and Civil and Mechanical Engineering, adaptive support structures and skins are developed within the Collaborative Research Centre SFB 1244. A holistic planning process is required in order to reduce the high complexity and achieve a goal-oriented procedure during the planning of such buildings and the development of integrated systems.

Part of this research is the development of new specific and the transfer of established methods from different disciplines. The experience gained during the planning of an adaptive, high-rise demonstrator building within the research project has shown that the methods for application must be provided in the form of a method toolbox to present their purpose, application time and results within the planning team. Based on the examination of existing method toolkits, this paper focuses on the development of an approach while considering context-specific requirements.
\end{abstract}

Keywords: Multi- / Cross- / Trans-disciplinary processes, Collaborative design, Design methods, Adaptive buildings, Method toolbox

\section{Contact:}

Honold, Clemens

University of Stuttgart

Institute for Engineering Design and Industrial Design

Germany

clemens.honold@iktd.uni-stuttgart.de

Cite this article: Honold, C., Leistner, S., Roth, D., Binz, H., Sobek, W. (2019) 'Method Toolbox for the 


\section{ADAPTIVE SKINS AND STRUCTURES}

The construction industry worldwide is associated with a high consumption of resources and is facing the challenge of a growing world population with scarce building materials. Adaptive skins and structures represent an approach for significantly reducing the high resource consumption of buildings throughout all phases of their lifecycle. With the integration of sensor-actuator systems in load-bearing structures, for example, the load transfer can be manipulated by means of small displacements. Peak stresses, which are caused by winds and earthquakes, are thus decreased, while building vibrations are damped. As a result, the design cross-sections can be reduced accordingly, and resources can be saved despite the energy required for actuation. (Sobek, 2016)

The static behavior of building skins can also be converted into a dynamic system. In the approach pursued, for example, the permeability of air, heat and sunlight is regulated according to demand and thereby results in a direct interaction between the interior and the environment (Haase et al., 2011). The basic advantages of adaptive skins and structures and their functionalities are being researched in the Collaborative Research Centre SFB 1244 funded by the German Research Foundation (DFG) in a project entitled "Adaptive Skins and Structures for the Built Environment of Tomorrow".

However, in comparison to conventional buildings, such adaptive buildings require much higher planning effort and an interdisciplinary planning team with disciplines that have typically not been involved in building planning thus far (Honold et al., 2017a). These include, for example, representatives from the disciplines of Mechanical Engineering and Control Engineering. As shown by Honold et al. (2016), and in order to support the complexity and the interdisciplinary cooperation, research must be conducted into a specific, generic planning process alongside the investigations in this paper. Furthermore, numerous interdisciplinary and discipline-specific methods are developed, while established existing methods are transferred for use in the planning of such buildings. Among others, these include methods for planning, design, form-finding, optimal actuator placement, energy demand, evaluating building physics concepts, sustainability and the development of a safety concept. The planning and construction of a twelve-story demonstrator high-rise is one essential part of the research activities within the Collaborative Research Centre. This building will be equipped with adaptive skins and structures. In addition to test purposes, the advantages of adaptive systems in this context will be demonstrated. Weidner et al. (2018), Wagner et al. (2017) and Ernst and Menges (2018) describe an interim status of the planning results and present a selection of applied methods. In the meantime, planning has reached the final phase, and ground has been broken for the foundations of the building. By participating in the planning of this building, the authors were able to gain experience with regard to the necessity of integrating, interlinking and applying the respective methods. Due to the experience possessed in the development and application of processes, methods, etc., it should be noted that this paper has been compiled in the research field of Design Methods with the involvement of architects in the research project.

The term "methods" is used in general language and, in particular, within a multidisciplinary research environment. In this context, the methods according to VDI 2223 (2004), Lindemann (2007, p. 56), Ehrlenspiel and Meerkamm (2017, p. 911) are interpreted as being planned, rule-based procedures within a sequence of activities to achieve a certain goal.

\section{PROBLEM STATEMENT AND GOALS}

New challenges become apparent during the planning of the demonstrator high-rise and student design studios for adaptive buildings supervised by the authors. In the context of this paper, several participants from different disciplines missed information concerning methods of other disciplines, meaning that interface definitions were not precise and that the overview of the planning progress was not clear. In addition, the participants were not able to recognize the potential and possibilities offered by the methods of other disciplines, which certainly limited the planning success. For the targetoriented planning of adaptive buildings, the application of the methods must be coordinated and integrated into the planning process to inform all participants and stakeholders involved about the purpose of the methods, the required input or suitable planning stages and the resulting outcome. To handle the complexity and effort involved, the planning process to be investigated must ensure a close interdisciplinary coupling between the participants, their tasks and the methods required in each case. 
In order to integrate the methods developed and those to be developed in the future into the planning process as effectively as possible, they must first be collected, recorded and categorized so as to demonstrate their versatility and their respective goals. The availability for future applications must be clearly arranged for the method users and for other participants involved in the planning of adaptive buildings. Furthermore, they must be supported in selecting methods for emerging planning situations. This goal is fulfilled by means of so-called method collections. If many methods within a collection can be flexibly combined in their respective application, as in this application scenario, the term "method toolbox" is also used (Krause and Gebhard 2018, p. 159). Method collections/toolboxes already exist for the most diverse applications of various specialist areas in which methods are applied. This method toolbox is supposed to ensure the interlinking of the interfaces between the planning process, methods researched and transferred during the research project, and the participants from the various disciplines involved.

The goal of this paper is therefore to answer the research question concerning the requirements that a method toolbox must fulfil in order to ensure high usability, application during the interdisciplinary planning and development of adaptive buildings, and the manner in which a method toolbox for this purpose might be realized. This paper contains a validated list of requirements for the method toolbox to be developed, a developed method profile and different concepts for clearly presenting and selecting methods.

\section{METHOD AND STRUCTURE}

Figure 1 illustrates the research approach and the structure of the paper. In order to systematically answer the research question, the paper is divided into two parts. Firstly, comprehensive literature research was conducted into how method toolboxes have been implemented to date and which characteristics they exhibit. In particular, the focus was set on the form of representation for the method selection. The determined concepts have been abstracted for comparability and are listed and explained in Section 4. The relevant literature already contained requirements for method toolboxes, which are summarized in Section 5.1. These requirements were supplemented by project-specific requirements identified during a workshop within the research project and presented in Section 5.2.

Based on this, the second part of the paper deals with the development of a specific method toolbox. As an essential part, Section 6 presents a profile for the collection and description of the methods. This method profile has already been employed to record the first methods for the method toolbox to be developed. Section 7 compares the concepts for the representation and method selection of Section 4 with the help of criteria derived from the requirements of Section 5. Research participants were therefore asked to evaluate the degree of fulfilment for each criterion and each approach for method collection. Section 8 discusses the results, and Section 9 presents an outlook for how the method toolbox will be refined further in subsequent steps.

\begin{tabular}{|c|}
\hline Literature research \\
\hline $\begin{array}{c}\text { Basics of method } \\
\text { toolboxes and selection } \\
\text { concepts (Section 4) }\end{array}$ \\
\hline $\begin{array}{c}\text { General requirements } \\
\text { for method toolboxes } \\
\text { (Section 5.1) }\end{array}$ \\
\hline
\end{tabular}

\begin{tabular}{|c|}
\hline Workshop results \\
\hline $\begin{array}{l}\text { Methods for planning } \\
\text { and developing } \\
\text { adaptive buildings }\end{array}$ \\
\hline $\begin{array}{l}\text { Requirements from the } \\
\text { research project } \\
\text { (Section 5.2) }\end{array}$ \\
\hline
\end{tabular}
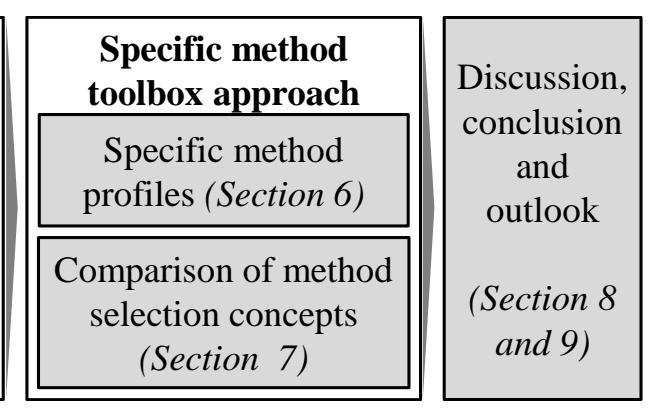

Figure 1: Research approach and structure of the paper

\section{EXAMPLES OF METHOD TOOLBOXES}

Ehrlenspiel and Meerkamm (2017, p. 434) describe method toolboxes as systematic collections of methods that can be alternatively utilized for certain work stages of a process. In addition, help is given for the selection of methods. Consequently, method toolboxes usually consist of descriptions of the methods contained therein as well as providing support in selection. In the context of developing a specific method toolbox for planning adaptive buildings, existing non-specific examples will first be analyzed. Literature research was conducted in order to obtain an overview of the different forms of 
description and basic possibilities for the selection support. No restrictions were set with regard to the subject area of the search results to gather a wide range of examples. The results are explained below. Textual descriptions or short profiles are generally employed for introducing the methods. Both fulfil the task of explaining the purpose of the method, the format of results and the rough approach. They also contain further information on the type of method (analysis or synthesis method), the degree of computer support or the assumptions which are to be made, for example. The content of the considered descriptions corresponds to the demands of the respective field of application. However, the structuring and graphic preparation of the methods for supporting the selection of the methods is much more versatile and demanding. This aspect will therefore be dealt with in more detail below.

According to VDI 2221 (1993), precise knowledge of all tasks, requirements and experience necessary for the respective development project, as well as the most important peculiarities and prerequisites of the methods, is required in order to select the best possible methods. The selection of methods from a method toolbox is generally supported by means of classifying criteria, which are used to classify the methods in the method toolbox. According to Ehrlenspiel and Meerkamm (2017, p. 437), typical criteria for classification and selection are "Purpose of the method", "Planning or development stage/work step", "Input data", "(Form of) result", "Effort/required resources", "Related disciplines" and "Other information".

The list of these typical selection criteria can be supplemented by specific criteria pertaining to the purpose of the method toolbox. In order to answer the question of how a selection of methods can be made based on the criteria, the results of the literature research concerning the selection concepts will be examined in more detail.

For the sake of comparison, the individual approaches of the examples identified were abstracted, while similar concepts were summarized. Table 1 lists the results in the form of five various concepts for the presentation and selection of methods and contains a brief description of the characteristics for each one. References are stated for where an appropriate example was found within the context of design methods. The illustrations are graphically prepared in such a way that they represent a sample section of the approach and illustrate the principle. Therefore, for the method table (first example) and method map (third example), different subcategories are chosen within the respective illustration in the left-hand column of Table 1 (e.g. qualitative/quantitative results of a problem analysis, intuitive or discursive search for solution, etc.), which is certainly less useful in practice.

At first glance, the selection concepts shown in Table 1 differ in principle with regard to the presentation format. However, similarities can be observed in the method table, matrix and map to the extent that only classification criteria were employed for classification. In both the method diagram and the method application timeline, the corresponding times required for the respective method's application are already considered due to a recognizable chronological sequence. This chronological classification requires knowledge of the associated (development) task unless it has been carried out too generally. Accordingly, these representations are only possible and meaningful if generic procedures or processes exist. The preparation of both representations therefore requires a preselection of the containing methods for the intended field of application. In the case of the first three concepts, however, one criterion might also concern the time of application (e.g. "suitable for early phase").

If generally applicable or problem-specific methods have to be selected on the basis of criteria with known characteristics, then the method table, matrix and map are suitable. Due to the simple filter function, the matrix is the most appropriate concept when a large number of methods has to be listed. The method table and map are advantageous in case that an alternative to a known method has to be selected as the registered methods can be found in the classification scheme next to those that meet the criteria with the same characteristics. Thus the first three examples are also suitable for very general applications with a focus on selection, whereas the last two are only suitable for specific applications with the aforementioned preselection of methods. One further distinction is that the methods and criteria are only listed once within the matrix. Since one method can meet several different constellations of criteria, especially with the method table and the method map, these can be listed several times. For such presentation formats, the portfolio technique can therefore be found twice in Table 1. As such, either the methods can be assigned to criteria or the criteria to the methods within the presentation formats.

The concepts presented form the basis for the further analysis and comparison in Section 7. This investigation presupposes comparative criteria to be identified in the form of requirements in Section 5 below. Section 6 presents a method profile for the toolbox to be developed based on these findings. 
Table 1. Concepts for presenting and selecting methods in method toolboxes

\begin{tabular}{|c|c|c|}
\hline \multicolumn{3}{|l|}{ Illustration } \\
\hline Problem analysis & Search for solutions & Assessment \\
\hline Qualitative & Intuitive & High score list \\
\hline $\begin{array}{l}\text { - Requirements } \\
\text { definition, T • } \\
\text { - .. }\end{array}$ & $\begin{array}{l}\text { - Brainstorming, } \mathrm{T} \\
\text { - Gallery method, } \mathrm{T} \\
\text { - } \ldots\end{array}$ & $\begin{array}{l}\text { - Concept scoring, } \mathrm{T} \\
\text { - Portfolio, } \mathrm{T} \bullet \\
\text { - } \ldots\end{array}$ \\
\hline Quantitative & Discursive & Key number \\
\hline $\begin{array}{l}\text { - Portfolio, } \mathrm{T} \bullet \\
\text { - Pareto analysis } \\
\text { - .. }\end{array}$ & $\begin{array}{ll}\text { - } & \text { Reverse } \\
\text { engineering, } \\
\text { - } & \text { Ordering schemes }\end{array}$ & $\begin{array}{l}\text { - } \text { Target costing, } \mathrm{T} \bullet \\
\text { - Amortization } \\
\text { calculation }\end{array}$ \\
\hline$\cdots$ & \multirow{2}{*}{\multicolumn{2}{|c|}{$\begin{array}{l}\text { Legend: } \\
\text { T Teamwork recommended } \\
\text { - Significant time required }\end{array}$}} \\
\hline$\ldots$ & & \\
\hline
\end{tabular}

\section{Characteristics}

\section{Method table}

- Tabular format, for example with main categories (e.g. purpose of the method) in columns and several subcategories in rows

- $\quad$ Selection by limiting the methods with the help of the presented criteria

- Further criteria can be specified as symbols after the names of the methods (e.g. $\mathrm{T}$ means "teamwork recommended" and - indicates a typically significant time requirement for the application)

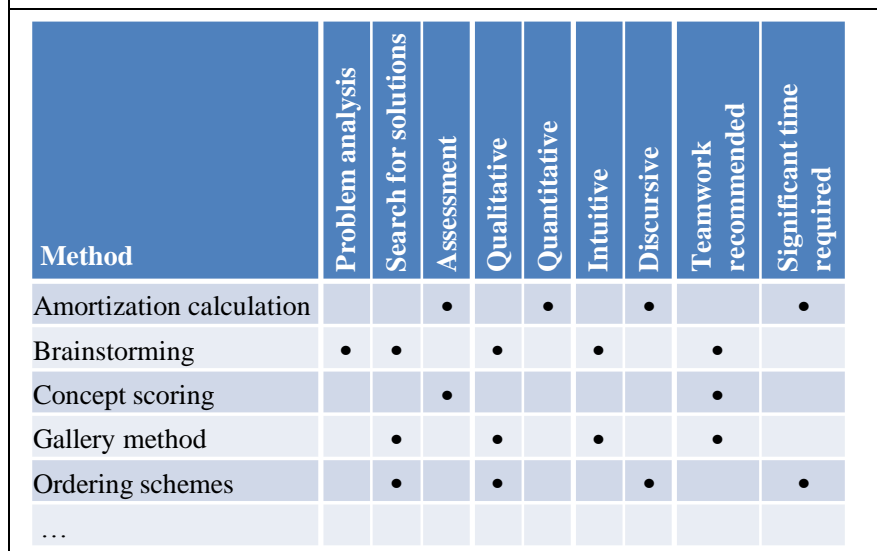

\section{Method matrix}

- $\quad$ Simple assignment of methods (e.g. in rows) to several criteria of a main category (in columns)

- The criteria represent a simple filter and can be selected as "must be" or "can be" criteria (not shown)

- The selection is made according to a selection list after the definition of case-specific criteria.

- $\quad$ Any number of criteria can be added

Based on VDI 2221 (1993)

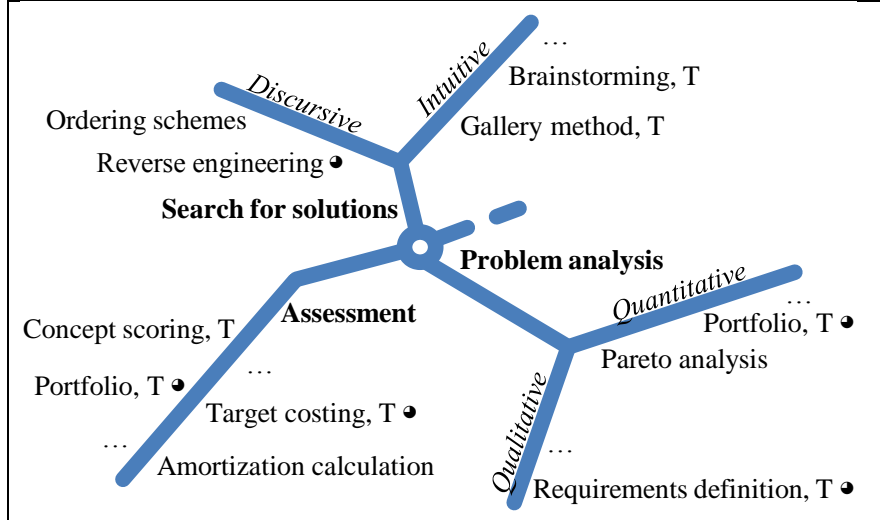

\section{Method map}

- Allocation of methods to paths that represent classifying categories (e.g. purpose of method such as "Problem analysis") with divisions according to subcategories (e.g. qualitative or quantitative results)

- Further criteria can be specified with symbols (compare with method table)

- The selection of methods is made by following the paths and considering the associated criterias and symbols.

Honold et al. (2019) developed a detailed method map for product development methods.

$\begin{aligned} & \text { Requirements } \\ & \text { definition, } \mathrm{T} \text { }\end{aligned}$
Schemes




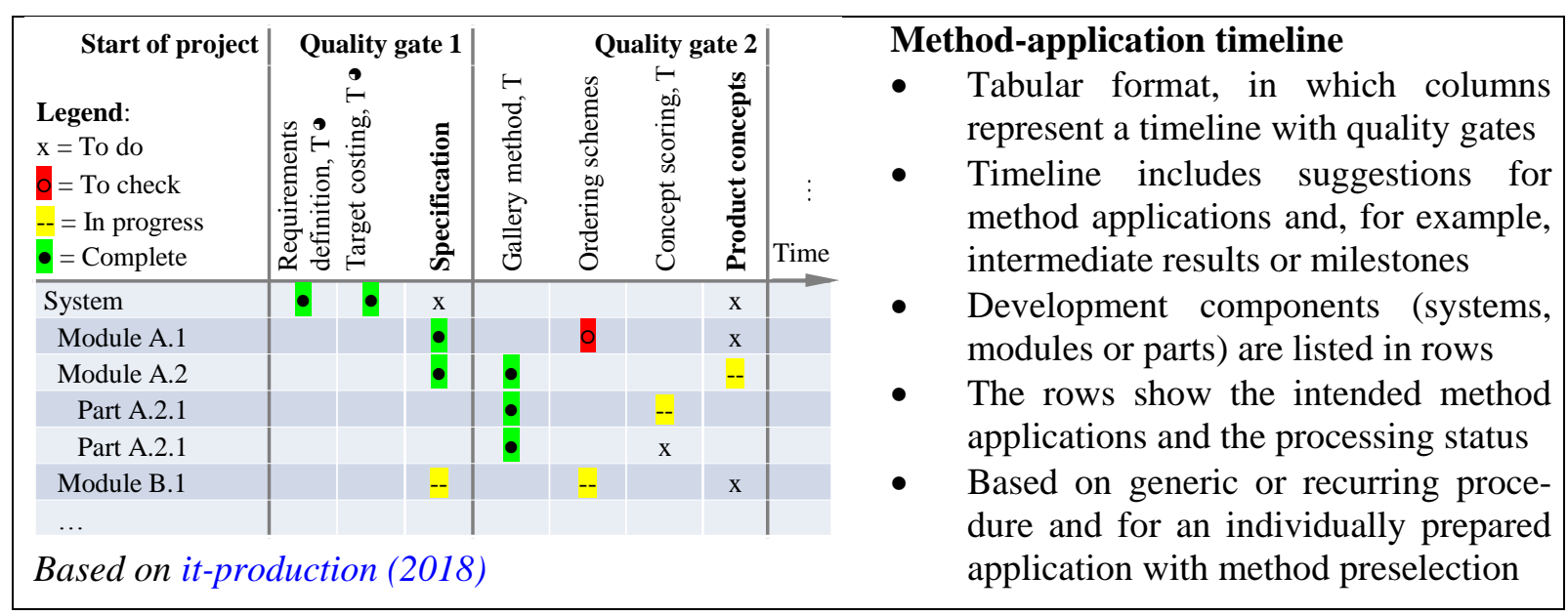

\section{REQUIREMENTS FOR METHOD COLLECTION}

This section summarizes the requirements imposed on the method toolbox to be developed for planning adaptive buildings. These requirements firstly consist of recommendations from literature that have been established during earlier developments of method toolboxes and, secondly, of conclusions resulting from project work. The following subsections are divided accordingly.

\subsection{General requirements for method toolboxes}

In order to obtain general requirements for method toolboxes, further literature research was conducted. For the field of Design Methodology, Ehrlenspiel and Meerkamm (2017, p. 435) list the following tasks which have to be fulfilled by method toolboxes in general (Section 7 refers to the passages highlighted in bold):

- Link tasks (work situations) with the processing methods that are appropriate for them

- Describe methods identifiably

- Provide selection criteria and instructions for the utilization of methods

- Serve as hints for where to learn more about the methods and how to learn them

- Be expandable and updatable

In addition to these special requirements for method toolboxes, reference is also made to the engineering-design method requirements identified by Keller and Binz (2009). However, the general results of this subsection are not specific to the problem presented in Section 2. Specific requirements must consequently be identified.

\subsection{Specific requirements for the method toolbox for planning adaptive buildings}

In order to develop the method toolbox in a goal-oriented manner, and in addition to the general requirements of Section 5.1, further context-specific requirements will be identified in this section. To this end, the problem was presented in a workshop and discussed with the goal of developing a method toolbox. The workshop involved researchers who develop methods for designing, planning and constructing adaptive buildings, in addition to members of the planning team for the demonstrator high-rise. The ten participants in total belong to the disciplines Architecture, Civil Engineering, Mechanical Engineering and System Dynamics. They are assigned to the specialist fields of Planning, Design and Construction Methods, Technical Mechanics, Form-Finding Methods, Control Engineering, Actuator Development, Lifecycle Assessment, and Reliability Engineering. All participants of the workshop were highly interested in developing a method toolbox for the planning process of adaptive buildings since some of the methods from other fields are not either familiar or represent an interface to their own particular research work or are suitable for transfer with regard to their own applications.

During the workshop, a process diagram was used to discuss how an adaptive structure should be conducted in an upcoming project of this kind based on the experience of the planning process for the previous demonstrator high-rise. After substantiating the needs and presenting the general requirements related to the interdisciplinary method toolbox, the workshop participants identified supplementary specific requirements. The authors subsequently clustered and summarized them: 
- Before and during the planning of adaptive buildings, the application of methods should be plannable with support of the method toolbox in order to consider interfaces and effort.

- In addition to the specific issue (Item 1 in Section 5.1), the methods should be assigned to the disciplines responsible, to the subordinate subject area or, alternatively, to the components (e.g. adaptive skin or structure) in order to support the allocation.

- With the support of the method toolbox, it should be apparent which influences exist between a specific method application and existing, concurrently developed or outstanding results yielded by other methods. Methods which specifically provide iterations over a longer period of time to improve their results should be marked accordingly to be prepared for potential changes.

- The methods should generally be represented in a comprehensible manner so that even generalists or participants from external fields can understand the goal, the rough procedure and the results yielded by the methods in addition to specialists.

- The (graphic) illustration concerning the procedure for selecting a method should be clearly structured and performed intuitively to achieve a quick and reproducible selection result. Furthermore, the level of formalization of the methods should be realized in the same manner.

Two further requirements identified for the toolbox for adaptive buildings are difficult to verify because they are more related to the application of the methods. Since methods in the conventional building planning process are rarely applied in practice (Schill-Fendl, 2004, p. 23), there should therefore be as few obstacles as possible to the selection and application of methods. In addition, the application of methods should support the collaboration of the participants as far as possible by providing assistance with the often-insufficient interdisciplinary planning processes. After specifying the requirements within the workshop, the applied methods or those to be newly developed in the research project were described. The following section outlines the result.

\section{METHOD PROFILES}

As already mentioned in Section 4, method toolboxes usually have brief descriptions of the considered methods. As an example, these can be implemented in the form of a method profile. For the further conception of the method toolbox for planning adaptive buildings, a profile was created which provides information on method selection according to the criteria from Section 4. In addition, the general and specific requirements of Section 5 concerning the method profile were considered in the implementation. In the second part of the aforementioned workshop, the method profiles were utilized by the participants to record around 30 of the methods and thus obtain an initial data basis for the method toolbox. The developed structure of the method profile is shown in Figure 2 with an example concerning the requirements engineering for planning and developing adaptive buildings.

\begin{tabular}{|c|c|c|c|}
\hline \multicolumn{3}{|l|}{$\begin{array}{l}\text { Requirements Engineering } \\
\text { Method name }\end{array}$} & \multirow{2}{*}{$\underset{\text { METHOD TOOLBOX }}{\text { SFB } 1244}$} \\
\hline $\begin{array}{l}\text { Analysis method/task clarification } \\
\text { Method type }\end{array}$ & $\begin{array}{l}\text { Honold, A01, IK } \\
\text { Name, Project, Institute }\end{array}$ & & \\
\hline \multicolumn{2}{|c|}{$\begin{array}{l}\text { The goal of Requirements Engineering (RE) in this context is to achieve and } \\
\text { promote a common understanding of the adaptive system to be planned or } \\
\text { developed within the multidisciplinary planning team. RE is divided into the } \\
\text { stages of task clarification (collecting, analyzing and documenting } \\
\text { requirements) and requirements management (releasing, versioning, modifying } \\
\text { and tracing requirements). } \\
\text { Method description (purpose and function) }\end{array}$} & \multicolumn{2}{|c|}{ 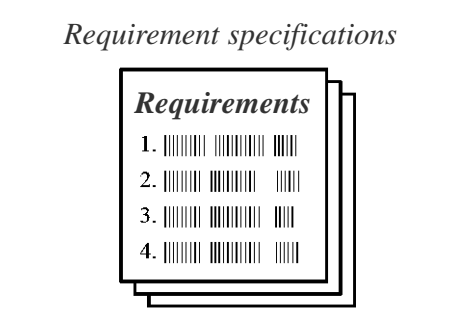 } \\
\hline \multirow{2}{*}{\multicolumn{2}{|c|}{$\begin{array}{l}\text { Requirement specification (e.g. in the form of a requirements list) containing } \\
\text { all requirements set for the result is continually updated and available for all } \\
\text { participants involved in the planning process. } \\
\text { Output information (including output format) }\end{array}$}} & \multicolumn{2}{|c|}{$\begin{array}{l}\text { E.g. requirement list } \\
\text { alization }\end{array}$} \\
\hline & & \multicolumn{2}{|c|}{$\begin{array}{l}\text { Project management } \\
\text { Responsible disciplines/participants }\end{array}$} \\
\hline \multicolumn{2}{|c|}{$\begin{array}{l}\text { Problem definition (e.g. project goals, boundary conditions) } \\
\text { Input information (necessary preparatory work) }\end{array}$} & \multicolumn{2}{|c|}{$\begin{array}{l}\text { Basic evaluation up to realization } \\
\text { Phase/work situation }\end{array}$} \\
\hline \multicolumn{2}{|c|}{$\begin{array}{l}\text { All stakeholders and representatives from the participating disciplines } \\
\text { Required resources (e.g. additional specialists, software etc.) }\end{array}$} & \multicolumn{2}{|c|}{$\begin{array}{l}\text { High }(100 \text { to } 150 \mathrm{~h}) \\
\text { Time requirement }\end{array}$} \\
\hline \multicolumn{2}{|c|}{$\begin{array}{l}\text { RE can be used with database support } \\
\text { Notes/further information (e.g. required assumptions) }\end{array}$} & \multicolumn{2}{|c|}{$\begin{array}{l}\text { Honold et al. (2017b) } \\
\text { Literature references }\end{array}$} \\
\hline
\end{tabular}

Figure 2: Sample method profile as a brief description for each method to be considered 
The method profile consists of a header with the name of the method, the method type and the assignment of the profile to the respective author. In the left-hand column, fields are provided in which the method is described with its purpose and function, output information (result and format), the necessary preparatory work as input information, required resources, and other notes. In the right-hand column the recognition value can be increased through a simple visualization. In addition, the assignment to the discipline and the planning phase or work situation is provided here. Information on the expected time required for the application using the example of the demonstrator high-rise and a literature reference to further information can also be found.

During the workshop, the method profiles could be utilized in a self-explanatory manner without exception for methods of different disciplines, purposes and method types. After this initial validation of the applicability, existing profiles will now be complemented by further profiles within the framework of future activities. Thus they can expand the method toolbox.

\section{COMPARISON OF METHOD-SELECTION CONCEPTS}

The goal of this section is to compare the abstracted selection concepts of the method toolboxes and to examine them with regard to the extent to which they fulfill the requirements set out. For this purpose, the concepts identified in Section 4 are compared with the requirements presented in Section 5. Therefore Table 2 lists the approaches in rows and the requirements in columns. For reasons of clarity, the latter are briefly summarized in a few terms and can be assigned to the terms highlighted in bold in the lists in Section 5. Since the reference, where to learn more about the methods (Item 4 of Section 5.1), and the cross-disciplinary comprehensible description (Item 4 of Section 5.2) relates to the implementation of the methods profiles, these requirements are not included in the comparison in Table 2. Item 2 of Section 5.2 is divided into "assign methods to disciplines or subject areas" and "assign methods to components" on account of the evaluability. When providing an answer to the degree of fulfilment, a distinction is made between not fulfilled (-), fulfilled in principle (o) and fulfilled (+). In a discussion on the advantages and disadvantages of the approaches presented, four participants belonging to the research field of Design Methods assigned the degrees. Below, the classifications of the degrees of fulfilment are briefly explained on the basis of the numbering (from 1 to 9) in Table 2:

1. Link tasks with methods: The method table, method matrix and method map can refer to tasks (e.g. "problem analysis") using selected categories, (+). In the method diagram, the path labels provide a direct link to the tasks (+). In the method application timeline, no tasks are directly recognizable (-).

2. Describe methods identifiably: The name of the method as well as additional symbols, categories or highlights describe and classify the methods in an identifiable way in all concepts $(+)$.

3. Provide selection criteria: The method table, matrix and map are feasible with the inclusion of a large number of selection criteria (+). The method diagram and the method application timeline allow the selection by using the link to process steps or tasks and the timeline. Due to the clarity (see point 4 ), the representation can only include a limited number of selection criteria or symbols (o).

4. Be expandable and updatable: All approaches are updatable. Expandability is also possible for all concepts, whereby the clearness and/or the size of the representation is to be considered. The required space must be taken into account for the method map and diagram in particular (o).

5. Support planning of method application: A direct reference to a process or the temporal connection is only discernable on the method diagram and the method application timeline. Thus, these representations show possible application times and their dependencies (+). In the other approaches, the effort, suitable phases, etc. can be depicted in principle (o) using the criteria.

6. Assign methods to disciplines or subject areas: The method names and the use of highlights, symbols, etc. can allocate the methods to the disciplines and subject areas in all approaches (+).

7. Assign methods to components: The allocation of methods to components of the individual application case is possible with the method application timeline via the listing of the components $(+)$. The other concepts can assign the methods only to categories of components, for example "structure parts" or "building skin", using categories or symbols (o).

8. Refer to influences of different method applications: Due to the process representation and linking of the work steps with the respective method applications, the influence of other results 
can only be seen on the method diagram (+). In the case of the method application timeline, these influences are discernible in principle due to the hierarchical presentation (o). The other approaches represent the methods independently of each other (-).

9. Clearly structured presentation: In all approaches the abstracted illustrations represent the structuring of the methods for a self-explanatory selection (+).

Table 2. Comparison of method toolboxes using general and identified specific requirements

\begin{tabular}{|c|c|c|c|c|c|c|c|c|c|}
\hline \multirow[b]{3}{*}{$\begin{array}{l}\text { Legend: } \\
\text { Degree of fulfilment } \\
\text { of the requirement } \\
\text { - Not fulfilled } \\
\text { o Fulfilled in principle } \\
\text { + Fulfilled } \\
\text { Approach: }\end{array}$} & \multicolumn{4}{|c|}{$\begin{array}{l}\text { General requirements } \\
\text { according to Ehrlenspiel } \\
\text { and Meerkamm (2017) }\end{array}$} & \multicolumn{5}{|c|}{$\begin{array}{l}\text { Specific requirements } \\
\text { identified by researchers of } \\
\text { adaptive buildings }\end{array}$} \\
\hline & 1. & 2. & 3. & 4. & 5. & 6. & 7. & 8. & 9. \\
\hline & 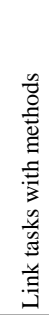 & 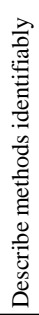 & 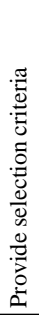 & 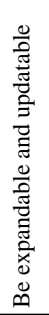 & 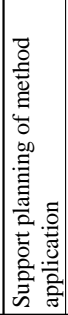 & 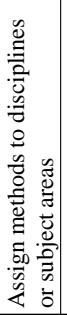 & 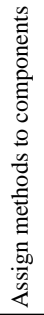 & 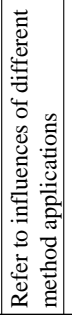 & 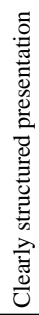 \\
\hline Method table & + & + & + & + & 0 & + & $\circ$ & - & + \\
\hline Method matrix & + & + & + & + & $\circ$ & + & $\circ$ & - & + \\
\hline Method map & + & + & + & $\circ$ & $\circ$ & + & $\circ$ & - & + \\
\hline Method diagram & + & + & $\circ$ & $\circ$ & + & + & $\circ$ & + & + \\
\hline Method application timeline & - & + & o & + & + & + & + & o & + \\
\hline
\end{tabular}

\section{DISCUSSION OF THE RESULTS}

The specific requirements (Section 5.2) have been generally documented so that the results are also suitable for other interdisciplinary development approaches. However, the general and specific requirements (Section 5) provide a suitable basis for the development of a method toolbox for planning adaptive buildings from the point of view of researchers' working in planning, design, and construction methods. During a workshop, which was already conducted in the course of the research project, newly developed, transferred and established methods from the participating disciplines could be recorded with the help of the presented method profiles (Section 6).

During the discussion of the workshop results, the potential for more closely identifying the dependency between the methods using the methods set out in the profiles was revealed. This examination would also correspond to the goal of the third specific requirement (Section 5.2) for analyzing the interaction between the method applications and their results in greater detail. Consequently, by assigning the methods to working phases, it is possible to identify those activities that have been supported so far with only insufficient or no methodological support. Therefore they require to be examined with regard to research needs. Thus the systematic visual presentation of methods offers further benefits compared to simple listings.

The comparison of the presentation and selection concepts for methods in Section 7 contrasts their advantages and disadvantages and allows the following conclusions to be drawn for further development. Not any concept presented optimally meets all stated requirements. However, each requirement is fulfilled by at least one concept. The method diagram is the only approach that fulfills each requirement at least "in principle". Moreover, this concept has the potential to present the methods together with the generic process to be developed by the authors for the planning of adaptive buildings. Thus, the method diagram supports the planning of method applications and shows the influence of other method applications by linking. However, the number of clearly presentable methods must be considered. As a consequence, a combination of the presentation and selection concepts is to be examined during the completion of the method toolbox.

\section{CONCLUSION AND OUTLOOK}

This paper presents an approach for a method toolbox to support the complex and demanding task of planning and developing adaptive buildings. The focus was set on the development of a method profile for the collection of initial methods for the research project, as well as on the comparison of concepts for presenting and selecting methods. The results are based on literature research and a 
multidisciplinary collection of requirements within the framework of a workshop considering practical experience during the planning of an adaptive high-rise building.

With regard to the future development of the method toolbox, several aspects should be considered. First of all, a further elaborated selection concept from Section 7 and the method profile from Section 6 will be combined to represent the essential components of a method toolbox. Subsequently, further context-relevant methods derived from literature research or the research results of the project will be added to complement the collection. Following on from this, the goal is to investigate which methods appear suitable for assignment to specific planning tasks, at which stage of the process and for which participants within the planning process for adaptive buildings. In order to validate and evaluate the requirements specified and the method toolbox itself, various experts from the construction industry and participants who are involved in the planning process of the demonstrator high-rise will be consulted. In addition, the methods will be analyzed with regard to their applicability within the framework of a future interdisciplinary design studio.

\section{REFERENCES}

Ehrlenspiel, K. and Meerkamm, H. (2017), Integrierte Produktentwicklung - Denkansätze, Methodeneinsatz, Zusammenarbeit, Carl Hanser Verlag, Munic, Wien.

Ernst, F., Menges, A. (2018), “Application of Parametric Modeling in the Early Design Phase for an Interdisciplinary Design Approach for Adaptive Buildings", Proceedings of the International Conference on Computational Methods (Vol. 5), Rome, Italy, 6th-10th August 2018, Liu, G.R., Trovalusci, P., Scientech Publisher LLC, USA, pp. 917-923.

Haase, W.; Klaus, T.; Schmid, T.; Schmidt, T.; Sedlbauer, K.; Sobek, W.; Synold, M. (2011), “Adaptive textile und folienbasierte Gebäudehüllen", Bautechnik, Vol. 88 No 2, pp. 69-75.

Honold, C.; Binz, H. and Roth, D. (2016), "Planning and developing Adaptive Buildings require methodical support”, NordDesign 2016 Conference, 10.-12. August 2016, Boks, C.; Sigurjonsson, J.; Steinert, M.; Vis, C. and Wulvik, A., Trondheim, Norway, Vol. 1, pp. 321-330.

Honold, C., Binz, H., Roth, D. (2017a), "Technical planning tasks and participants involved in planning Adaptive Buildings", 21st International Conference on Engineering Design 2017, Vol 1: Resource Sensitive Design | Design Research Applications and Case Studies, Vancouver, Canada, 21.-25. August 2017, p. 131.

Honold, C., Binz, H., Roth, D. (2017b), "Requirements Engineering für die Planung und Entwicklung adaptiver Bauwerke”, Stuttgarter Symposium für Produktentwicklung 2017, Stuttgart, June 29, 2017, Binz, H., Bertsche, B.; Bauer, W.; Roth, D., Stuttgart.

Honold, C., Fischer, S., Roth, D., Binz, H. (2019), "Methodenlandkarte zur Auswahl von Produktentwicklungsmethoden im interdisziplinären Kontext”, Stuttgarter Symposium für Produktentwicklung 2019, Stuttgart, Mai 16, 2019, Binz, H., Bertsche, B.; Bauer, W.; Roth, D., Stuttgart.

it-production (2018), Available at: https://www.it-production.com/allgemein/engineeringframeworkssystembaukasten-fuer-die-produktentwicklung/ (12.11.2018)

Keller, A., Binz, H., (2009), "Requirements on engineering design methodologies”, International Conference on Engineering Design 2009, Vol 2: Design Theory and Research Methodology, Palo Alto, CA, USA, 24.-27. August 2009, pp. 203-214.

Krause, D., Gebhard, N. (2018), Methodische Entwicklung modularer Produktfamilien - Hohe Produktvielfalt beherrschbar entwickeln. Springer Vieweg, Berlin, Heidelberg.

Lindemann, U. (2007), Methodische Entwicklung technischer Produkte, Springer-Verlag, Berlin, Heidelberg.

Schill-Fendl, M., (2004), Planungsmethoden in der Architektur, Doctoral thesis, TU Dresden.

Sobek, W. (2016), "Ultraleichtbau / Ultra-Lightweight Construction”, GAM.12 Architecture Magazine, Birkhäuser, Basel, pp. 156-167.

VDI 2221 (1993), Systematic Approach to the Design of Technical Systems and Products, VDI-Verl., Düsseldorf.

VDI 2223 (2004), Systematic embodiment design of technical products, VDI-Verlag, Düsseldorf.

Wagner, J., Heidingsfeld, M., Böhm, M., Sawodny, O. (2017), "Gramian-Based Actuator Placement for Static Load Compensation in Adaptive Structures”, 7th GACM Colloquium on Computational Mechanics for Young Scientists from Academia and Industry, von Scheven, M., Keip, M.-A., Karajan, N., Stuttgart.

Weidner, S.; Kelleter, C.; Sternberg, P.; Haase, W.; Geiger, F.; Burghardt, T.; Honold, C.; Wagner, J.; Böhm, M.; Bischoff, M.; Sawodny, O.; Binz, H. (2018), "The implementation of adaptive elements into an experimental high-rise building", Steel Construction, Vol. 11 No. 2, pp. 109-117.

\section{ACKNOWLEDGMENTS}

The authors gratefully acknowledge the generous funding of this work by the German Research Foundation (DFG - Deutsche Forschungsgemeinschaft) as part of the Collaborative Research Centre 1244 (SFB) "Adaptive Skins and Structures for the Built Environment of Tomorrow", project A01. 